6-2003

\title{
Design, Implementation, And Integration of An Experiential Assembly System Engineering Laboratory Module
}

Andres L. Carrano

Michael E. Kuhl

Matthew M. Marshall

Follow this and additional works at: https://digitalcommons.fairfield.edu/engineering-facultypubs (C) 2003 American Society for Engineering Education

\section{Peer Reviewed}

\section{Published Citation}

Kuhl, M., \& Marshall, M., \& Carrano, A. (2003, June), Design, Implementation, And Integration Of An Experiential Assembly System Engineering Laboratory Module Paper presented at 2003 Annual Conference, Nashville, Tennessee. 10.18260/1-2--12486

This item has been accepted for inclusion in DigitalCommons@Fairfield by an authorized administrator of DigitalCommons@Fairfield. It is brought to you by DigitalCommons@Fairfield with permission from the rightsholder(s) and is protected by copyright and/or related rights. You are free to use this item in any way that is permitted by the copyright and related rights legislation that applies to your use. For other uses, you need to obtain permission from the rights-holder(s) directly, unless additional rights are indicated by a Creative Commons license in the record and/or on the work itself. For more information, please contact digitalcommons@fairfield.edu. 
Session 2357

\title{
DESIGN, IMPLEMENTATION, AND INTEGRATION OF AN EXPERIENTIAL ASSEMBLY SYSTEM ENGINEERING LABORATORY MODULE
}

\author{
Andres L. Carrano, Michael E. Kuhl, Matthew M. Marshall \\ Industrial \& Systems Engineering Department \\ Rochester Institute of Technology \\ Rochester, NY 14623 USA
}

\begin{abstract}
Curriculum integration and multidisciplinary studies have become key issues in improving engineering education. This paper presents the design and implementation of laboratory material that integrates three traditionally independent courses in the industrial engineering curriculum, manufacturing, ergonomics, and simulation, utilizing an experiential assembly system. This collaborative project incorporates a team-based learn-by-doing approach to the theoretical knowledge in these subject areas ${ }^{1,3}$. These components are implemented in a dynamic and reconfigurable environment in which the students are given the opportunity of contrasting his/her design against the working reality. The results of this project are discussed along with the impact on the curriculum.
\end{abstract}

\section{Introduction}

In industry, there is a constantly growing need for engineers possessing both academic and technical proficiencies. Meeting this need requires different and more innovative ways to impart knowledge. Traditional lecturing is an excellent mechanism for delivering large amounts of information but it also encourages passivity in students and compromises their interaction in class $^{2}$. This also dulls student creativity since the instructor is expected to provide all the necessary material and ideas. On the other hand, traditional laboratory experiences tend to be very focused and rigid on a specific topic, consequently lacking an integrative approach that comprises different fields of academic instruction. The aim of this paper is to present a collaborative project in which we develop an interactive laboratory module that integrates course material from three traditionally independent areas within industrial engineering.

This effort involves the collaboration of faculty to develop integrated laboratory-based teaching modules in the areas of manufacturing, ergonomics, and simulation that utilize a common experimental assembly system. The manufacturing module addresses assembly systems engineering issues, production volume and rate considerations, and assembly quality considerations. The ergonomics component focuses on evaluating the physical demands of the system and how these relate to the physical capabilities and attributes of the human worker. The simulation component, focuses on creating computer-based simulation models of the system,

"Proceedings of the 2003 American Society for Engineering Education Annual Conference \& Exposition Copyright (C) 2003, American Society for Engineering 
conducting experiments on the model, and drawing conclusions from the model about the behavior of the real system. All these components are implemented in a dynamic and reconfigurable environment in which the students are given the opportunity of contrasting his/her design against the working reality. The uniqueness of this project resides in providing for concurrent development of hands-on material for three core areas of industrial engineering in a common arena.

\section{Motivation and Targeted Learners}

The basic motivation for undertaking this project was to strengthen the industrial engineering curriculum at Rochester Institute of Technology (RIT). To do this, we wanted to provide a more integrated approach to teaching courses such as manufacturing, ergonomics, and simulation which are traditionally thought of as independent topics. Furthermore, the experiential setup will allow the incorporation of a team-based learn-by-doing approach to the theoretical knowledge in the areas of manufacturing, simulation and ergonomics and their interrelationship by being exposed to all the different facets of assembly systems engineering.

Typically, a graduate from an industrial engineering program is expected to perform and contribute in all the areas mentioned above, sometimes in a common arena. However, the instruction provided to the students is usually isolated by course and without a strong and explicit connection across courses. This approach will provide the student with the opportunity of looking at the same process from three different perspectives, thus imitating real working environments. Additionally, the hands-on approach and open-ended nature of this experience could result in a more effective way of communicating and instructing, as well as improved student's knowledge retention and assimilation. A higher level of student motivation and involvement was one of the expected outcomes since this interactive approach tends to be more appealing to the student.

The targeted student population includes all undergraduate students in the third and fourth year of Industrial and Systems Engineering at RIT. (Note that this program is a 5-year program which includes 1 year of mandatory co-op experience, and the academic year follows a quarter system.) Under the current curriculum, students take courses in manufacturing engineering and ergonomics during the third year and simulation during their fourth year.

\section{The Assembly System}

The assembly setup utilized in this study consisted of four tubular-aluminum workstations linked by a manual, dual track conveyor. This system is configurable in the following layouts: straight line, L-shape, U-shape, and closed loop (oval). The dual track system provides a dedicated return track for the roller pallets. Each workstation has a half-moon working surface for easy reach to the overhead accessories. Accessories such as bins, shelves, flow-through and push-back racks, light fixtures, tool balancers, status lights, etc., are used to provide an efficient assembly environment. Figure 1 shows the assembly system in use during the project. 


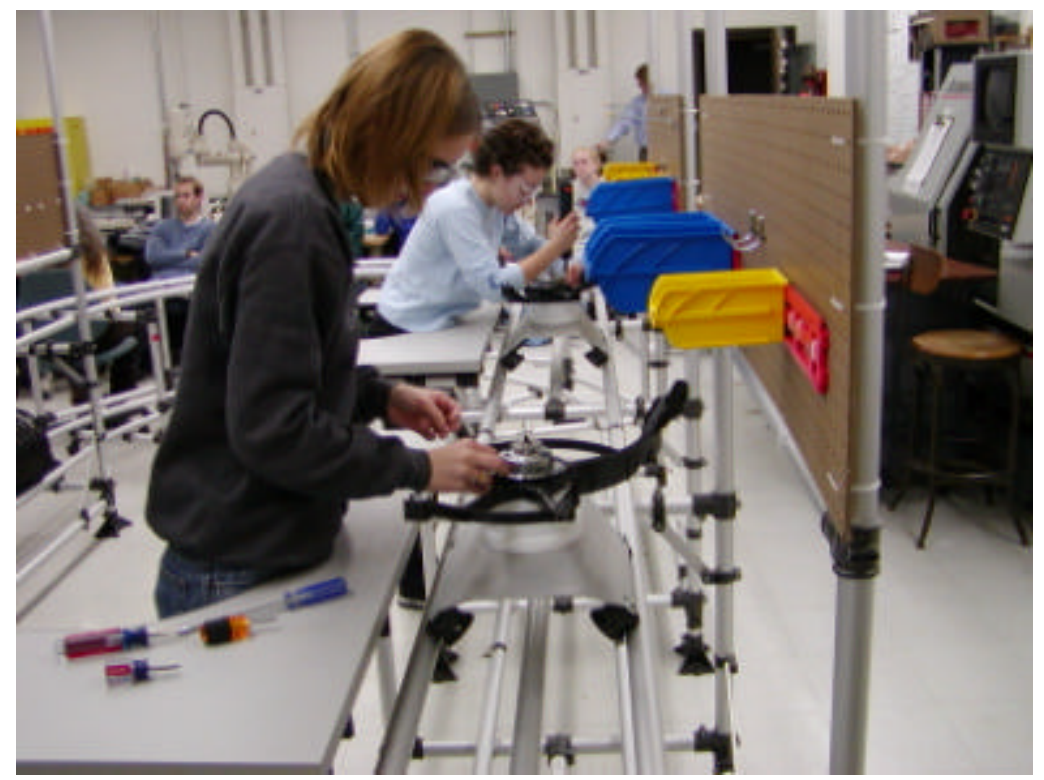

Figure 1. Experiential Assembly System

The case study used in this experience was an automobile radiator fan assembly shown in Figures 2 and 3. This consisted of 50 assemblies donated by a local first-tier supplier to one of the big-three automakers. The assembly consisted of a base shroud, a motor subassembly, a 3blade fan, three 1/4"-20 flat screws with washers, and a reverse-thread wing nut. Assembly fixtures were manufactured in-house and attached to the roller pallets to facilitate the assembly process and provide stability during transportation.

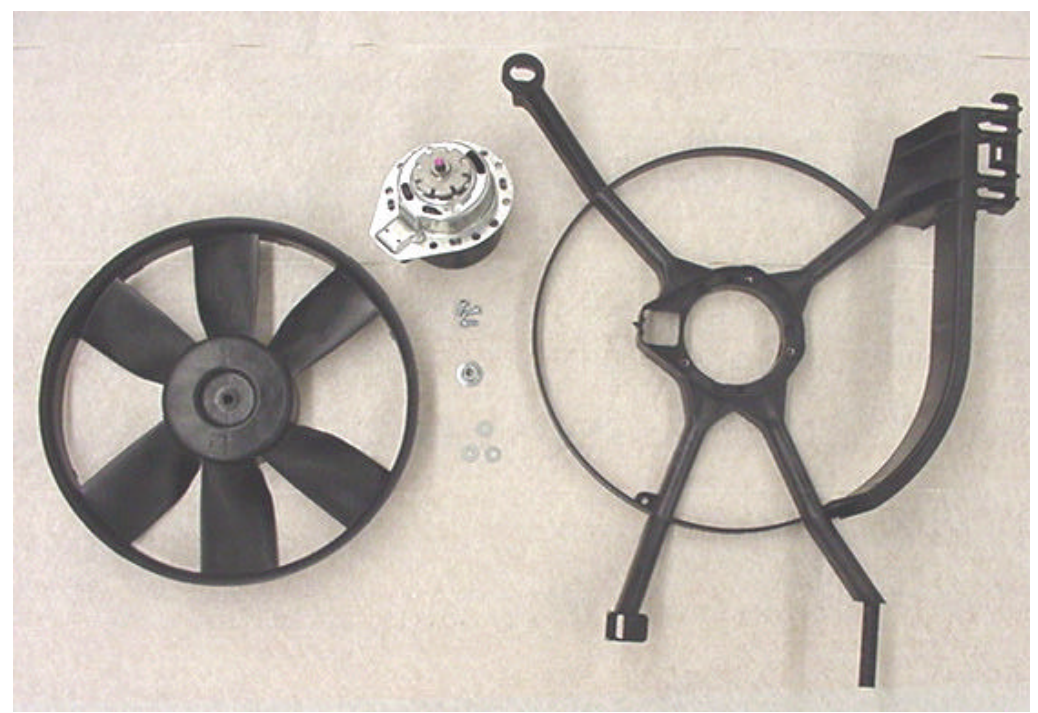

Figure 2. Individual Components of Fan Assembly 


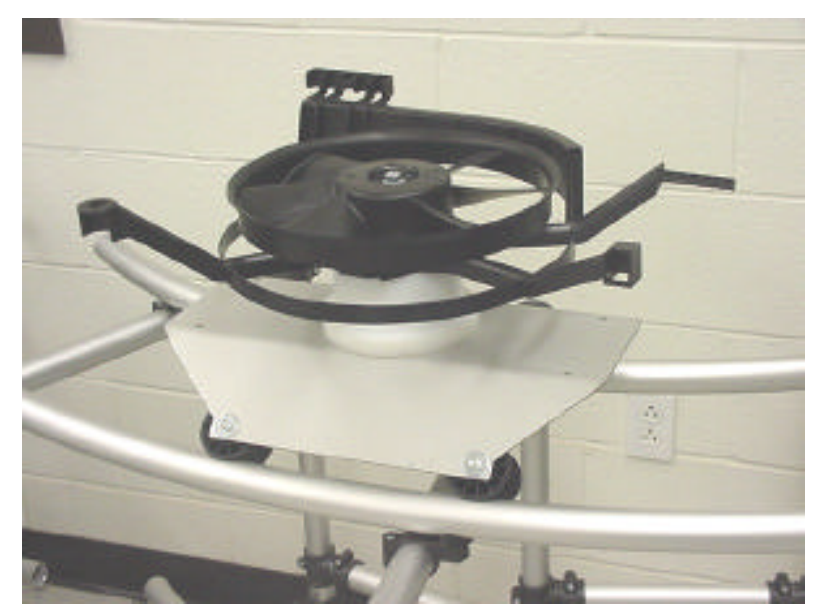

Figure 3. Automobile Radiator Fan Assembly on a Roller Pallet

The entire system is modular and very easy to reconfigure in less that one-half hour. The line can be laid out and connected and the workstations can be modified (i.e. type and location of bins, tools, etc.) in little time. Under this environment, the students are able to study the product (dissection and reverse engineering), study the assembly process (task division and precedence, time study, workstation design, computer simulation, etc), design several alternatives of the entire process (line layout, number and type of workstations, pace of assembly, etc), implement the best design, and conclude the activity with a real pilot run on the line. Furthermore, this flexible system allows for different group s to design and implement different solutions.

\section{Laboratory Modules}

Each of the three laboratory modules was conducted during the academic quarter in which the corresponding class was taught. Each of these modules is described separately below.

\subsection{Manufacturing}

The manufacturing portion of this study was conducted in the Fall quarter of 2002 as part of the undergraduate mandatory course "Manufacturing Engineering" for all ISE students. During this course, the students were walked through the manufacturing sequence of such product as shown in the following schematic

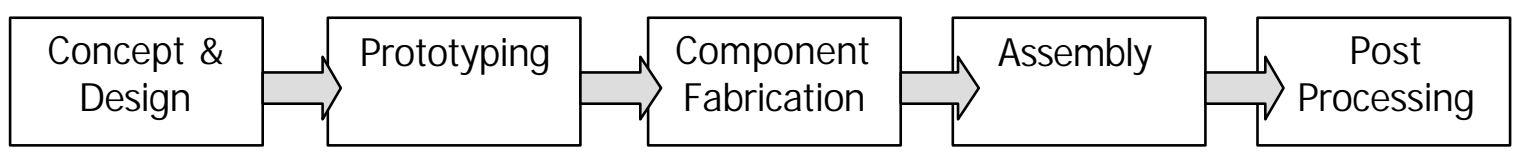

Figure 4: Manufacturing Sequence

At the stage of assembly, the students were sufficiently familiar with the individual parts composing the assembly and the issues around them (i.e. manufacturing processes, materials, etc). The students worked in teams and were assigned the general task of designing the assembly line for this product. This required subdividing the assembly tasks down to the smallest work

"Proceedings of the 2003 American Society for Engineering Education Annual

Conference \& Exposition Copyright (C) 2003, American Society for Engineering 
elements, familiarizing themselves with the assembly operations, developing and capturing tool and fixture requirements, performing time studies on the tasks, performing capacity and throughput analysis from this data, designing the macro configuration of the assembly line (i.e. layout and general flow configuration) as well as designing micro aspects of the system (raw workstation design and flow within workstations, tooling, fixtures and component storage) and performing line balancing and task allocation by using LOB algorithms. At this point, the students had proposed a full design of the assembly line based on their analyses. They also had projections and estimates of the performance of the proposed system.

The final experience was to perform a one-half hour pilot run with the students running the assembly line with the configuration and design they proposed. During this time, they simulated three 10-min shifts and rotated around workstations. Data recorded on a continuous basis included throughput and number of defective assemblies. Data on the status of the system was collected every 5 minutes. This included the state of the line such as workstation utilization, accumulations on queue, starving workstations, blocked workstation and WIP in system. A discussion at the end of the experience reflected upon the discrepancies between the theoretical and actual performance.

\subsection{Ergonomics}

The Ergonomics component of the project analyzed the relationship between the physical dimensions of the workstation and the anthropometric characteristics of the target "worker" population, who for the purposes of the lab was represented by the students in class. Students performed anthropometric measurements on the class as well as measurements of the vertical and horizontal location of the parts bin. Then by comparing the reach dimensions of the workers to the layout of the workstation, students were able to assess the compatibility and recommend design modifications.

Since the Ergonomics module took place the quarter after the Manufacturing and Simulation modules, videotape obtained during the previous quarter was used to reacquaint the students with the assembly process prior to data collection. Several frames from this footage are presented in Figure 1. The video was used as a basis for introducing the problem and discussing the students' impressions and observations of how well the workstations fit them. The first part of the data collection required the students to conduct an anthropometric survey of the class. Using meter sticks and tape measures, students identified the appropriate anatomical landmarks on each other and measured anthropometric variables such as stature, knee height, and wrist-wall length, among many others. Students then obtained measurement of the vertical and horizontal location of the parts bin used in the assembly operation. Using these data, students then prepared an overlay plot of the workstation dimensions along with the horizontal and vertical reach envelopes in the sagital plane for a $5^{\text {th }}$ percentile female and a $95^{\text {th }}$ percentile male. From these diagrams students were able to evaluate the suitability of the workstation design by observing the overlap (or lack thereof) between the reach envelopes and the work location. To report their results students prepared a written laboratory report, complete with sketches of the workers and workstations before and after redesign.

"Proceedings of the 2003 American Society for Engineering Education Annual Conference \& Exposition Copyright (C) 2003, American Society for Engineering Education" 


\subsection{Simulation}

The simulation component of this project included all aspects of a simulation study from start to finish. The students were shown the reconfigurable assembly/material handling system and the products that were to be assembled. The students were also given the very general task of designing an efficient assembly system, and they were given approximately 5 weeks to complete the entire project.

Following the steps of the simulation study taught in the lecture, the first step was to define the problem, its scope, and measures of performance. That is, the students defined what was considered to be an efficient assembly system. For this system, they defined an efficient system one that resulted in high throughput, low cycles times, low work-in-process inventory, and low cost. The next step was to apply techniques taught in the manufacturing class to break down the assembly process into individual tasks and collect data on the time to perform each task. Using distribution fitting software, probability distributions were fit to the assembly times for each task to be used as input to the simulation model. Using simulation software, a simulation model of the system was constructed for each alternative system configuration that the students identified. The simulation models were verified and validated using techniques such as traces, structured walkthroughs of the model, etc. After designing a set of experiments (determining the number of replications, length of replications, etc.), the simulation models were run and the output of the simulation runs were analyzed by constructing confidence intervals on the output performance measures. The system configurations were compared both from a statistical point of view and from a practical, engineering perspective. The students then made a recommendation for the most efficient assembly system design. Note that among the factors influencing the decision about the most efficient system were ergonomic factors such as personal time allowances when considering the utilization of the workers.

The entire simulation study was documented in the form of a web-page which allows for the inclusion of the simulation models, data files, etc. as part of the final report and allows other students to view and learn from the project. Finally, as discussed further in the next section, the students in the simulation course gave a presentation to the students in the manufacturing course, who in turn, implemented the recommended system configuration in a pilot production run.

\section{Implementation and Integration}

This project has enabled students to learn and apply the various industrial engineering techniques of manufacturing, ergonomics, and simulation in a common setting with the goal of educating the students not only in the specific engineering methods but also in the integration and interdependence of these methods and their impact on decisions about system design and implementation.

Specifically, the integration of the laboratory modules for the three courses using the assembly system included the industrial engineering techniques of dividing the assembly process into individual tasks, collecting data on the time required to perform each task, fitting probability distributions to the observed data, utilizing the distribution as input to the simulation models, evaluating alternative system configurations, and developing ergonomically sound workcells to

\footnotetext{
"Proceedings of the 2003 American Society for Engineering Education Annual Conference \& Exposition Copyright (C) 2003, American Society for Engineering Education"
} 
completely design the assembly system. Perhaps the most important aspect of project was the ability to fully implement the recommended system configuration and perform a pilot production run using the actual system to assemble the products.

\section{Results and Observations}

In addition to the regular student evaluation form required by the college, an independent questionnaire was distributed among the students at the end of the fall quarter. The population size was 24 students and the total number of responses (returned questionnaires) was 23 .

Some of the results from this survey include:

- 15 students ranked this assembly experience in the top two activities they liked the most overall.

- 20 students agreed they were more likely to remember the content delivered in these courses because of this experience.

- When compared to other traditionally-taught courses they had previously taken, 23 students preferred this approach over the traditional one.

Aside from the survey results, several other outcomes were observed or realized:

- Students actively participated (with enthusiasm) in all aspects of the laboratory;

- The interrelationships among manufacturing, ergonomics, and simulation issues were emphasized;

- Having been exposed to the assembly system in one class, time was saved by not needing to reorient or introduce the students to the system; and

- The use of the assembly system is also being integrated into an introductory course to IE to study and demonstrate the topic of work measurement.

As we continue to utilize these laboratory modules we expect that other benefits will be realized. Additionally, we will use more surveys to assess the effectiveness of the modules.

\section{Conclusion}

In summary, the implementation of the experiential assembly system has fostered the integration of three traditionally independent areas of industrial engineering, manufacturing, ergonomics, and simulation. Through the development of these three laboratory modules, students are provided with a hand-on approach to these subjects where they can fully, and actively participate in all aspects of the design and implementation of the assembly system. Further, the interrelationships among manufacturing, ergonomics, and simulation in terms of their impact on design and implementation can be integrated in a common arena. Finally, this project can serve as a template for the integration of curriculum topics of other disciplines. 
1. Carrano, A.L. and J.B. Taylor. "Cooperative Learning Factories and Their Impact on Learning Styles". Tekhné Journal, Vol. 3 pp. 17-25. Universidad Catolica Press. Venezuela. 1999.

2. Felder, R.M. and L.K. Silverman, "Learning and Teaching Styles in Engineering Education," ASEE, Journal of Engineering Education, Vol. 78, No. 7, pp. 674-681. 1988.

3. Lamancusa, J.S., J.E. Jorgensen, and J.L. Zayas-Castro, "The Learning Factory -- A New Approach to Integrating Design and Manufacturing into Engineering Curricula", ASEE, Journal of Engineering Education, Vol. 86, No. 2, pp. 103-112. 1997.

ANDRES L. CARRANO is an assistant professor in the Department of Industrial and Systems Engineering at Rochester Institute of Technology. His teaching and research interest include manufacturing processes and systems. $\mathrm{He}$ is a member of ASEE, SME, IIE, and FPJ.

MICHAEL E. KUHL is an assistant professor in the Department of Industrial and Systems Engineering at Rochester Institute of Technology. His teaching and research interests include simulation modeling and analysis, and operations research. He is a member of ASEE, IIE, and INFORMS.

MATTHEW M. MARSHALL is an assistant professor in the Department of Industrial and Systems Engineering at Rochester Institute of Technology. His teaching and research interest include ergonomics, human factors, and biomechanics. He is a member of IIE and HFES. 